\title{
Avaliação da contaminação por bactérias em cédulas e moedas circulantes em cantina do Centro Universitário de Volta Redonda - UniFOA
}

\section{Assessment of contamination by bacteria in bills and coins circulating in a cafeteria at the University Center of Volta Redonda - UniFOA.}

\author{
Sabrina Silva Pêgas ${ }^{1}$ \\ Beatriz Rabello ${ }^{2}$ \\ Eduardo Massahide Kawakami² \\ Fernanda Assis Mello ${ }^{2}$ \\ Carlos Alberto Sanches Pereira ${ }^{3}$ \\ 1 Graduação em Ciências Biológicas ênfase em Biotecnologia, Centro Universitário de Volta Redonda - UniFOA.
2 Discente de Medicina do Centro Universitário de Volta Redonda - UniFOA.
3 Docente do Centro Universitário de Volta Redonda - UniFOA.
}

\section{RESUMO}

O presente trabalho teve como objetivo avaliar a presença de bactérias existentes em cédulas e moedas circulantes em uma das cantinas do Centro Universitário de Volta Redonda. Para tanto, as cédulas e moedas foram acondicionadas em um saco plástico e encaminhadas para análise no laboratório. Com auxilio de um swab, foi extraído das mesmas o material a ser analisado, seguindo de diluições decimais, as quais foram plaqueadas em placas de Petri com ágar Mueller Hinton e mantidas a $37^{\circ} \mathrm{C}$ por 24 horas. Nas moedas, as maiores médias encontradas foram nos exemplares de $\mathrm{R} \$ 1,00$, com média de 133,3 UFC/moeda e, nas moedas de R\$ 0,05, com a média de 166,6 UFC/moeda. Já as menores médias foram encontradas nas moedas de R\$ 0,10, com 50 UFC/ moeda; R\$ 0,25, com 10 UFC/moeda e nos exemplares de $R \$ 0,50$, com quantitativo de 6,6 UFC/moeda, sendo esta a menor media encontrada. Nas cédulas, as maiores médias foram encontradas nos exemplares de $R \$ 50,00$, com 4.873 UFC/cédula e R\$ 10,00, com 426,6 UFC/cédula, enquanto as menores médias foram encontradas nos exemplares de $\mathrm{R} \$ 20,00$, com 213,3 UFC/cédula; R\$ 5,00, com 183,3 UFC/cédula e nas de R\$ 2,00, com 146,6 UFC/ cédula. Com base nos resultados, pode-se concluir que cédulas e moedas apresentaram-se contaminadas e que esse tipo de contaminação representa risco à saúde pública.

\section{Palavras-chave}

Cédulas; moedas; contaminação bacteriana.

\section{ABSTRACT}

The present study aimed to evaluate the presence of bacteria on banknotes and coins circulating in one of the cafeterias at the University Center of Volta Redonda. For that purpose, the bills and coins were placed in a plastic bag and sent to laboratory analysis. With the aid of a swab, the material to be analyzed was taken from them, followed by decimal dilutions, which were placed in Petri dishes with Mueller Hinton agar and maintained at $37^{\circ} \mathrm{C}$ for 24 hours. On the coins the highest averages were found on the $R \$ 1.00$ samples with an average of 133.3 CFU/coin and on the coins of $R \$ 0.05$ the average of $166.6 \mathrm{CFU} / \mathrm{coin}$; the lowest averages were found on the coins of $R \$ 0.10$ with $50 \mathrm{CFU} /$ coin, $R \$ 0.25$ with 10 CFU/coin, and samples of $R \$ 0.50$ with a quantitative of $6.6 \mathrm{CFU/coin,} \mathrm{the} \mathrm{last} \mathrm{being} \mathrm{the} \mathrm{lowest} \mathrm{average}$ found. On banknotes, the highest means were found on samples of $R \$ 50.00$ with $4,873 \mathrm{CFU} /$ bill and $R \$ 10.00$ with $426.6 \mathrm{CFU} /$ bill; the lowest means were found on samples of $R \$ 20.00$ with $213.3 \mathrm{CFU} / \mathrm{bill}, \mathrm{R} \$ 5.00$ with 183.3 CFU/bill and the $R \$ 2.00$ with $146.6 \mathrm{CFU} / \mathrm{bill}$. Based on these results, we can conclude that bills and coins are infected and this type of contamination poses a risk to public health.

\section{Keywords}

Banknotes; coins; bacterial contamination.

\section{Como você deve citar?}

PEREIRA, Carlos Alberto Sanches et al. Contaminação por bactérias em cédulas e moedas circulantes em cantina do Centro Universitário de Volta Redonda - UniFOA. Cadernos UniFOA, Volta Redonda, n. 27, p. 75-81, abr. 2015. 


\section{INTRODUÇÃO}

As bactérias possuem extrema facilidade de sobreviverem em diversos tipos de ambientes, incluindo até mesmo objetos de uso diário, como é o caso das cédulas e moedas, principalmente se as mesmas forem utilizadas continuamente em contato com mãos, tornando-se um eficiente veículo de contaminação (REIS et al., 2010).

Cédulas e moedas, por serem o combustível que impulsiona a economia, exercem um importante papel dentro da sociedade e com isso são imprescindíveis para a manutenção de nossas vidas. Por meio delas, é possível realizar várias atividades, como alimentação, viagens, estudos, e aquisição de bens, entre outras coisas (SOUZA et al., 2006). Com toda essa importância, as cédulas e moedas adquiriram intensidade em sua circulação e a todo o momento é possível observar seu contato direto com as mãos das mais variadas pessoas, que, na maioria das vezes, não fazem uso de medidas básicas de higiene, possibilitando que elas sejam agentes transmissores dos mais variados tipos de micro-organismos (FERREIRA et al., 2012).

Segundo Awe et al. (2010), o hábito de guardar cédulas e moedas em locais próximos à pele, manipulá-las após o uso do banheiro sem lavar as mãos ou deixá-las diretamente em contato com superfícies sujas pode ser considerado fator que favorece e contribui para o desenvolvimento da contaminação.

O presente trabalho teve como objetivo quantificar a população de bactérias presentes nas cédulas e moedas em circulação em uma das cantinas do Centro Universitário de Volta Redonda - UniFOA.

\section{MATERIAL E MÉTODOS}

O presente trabalho foi desenvolvido nas instalações do Centro Universitário de Volta Redonda - UniFOA, incluindo uma cantina e o laboratório de Biotecnologia.

\subsection{Coleta das Amostras}

As cédulas e moedas foram coletadas por meio de trocas estabelecidas com o funcionário responsável da cantina. As trocas ocorreram três vezes consecutivas, estrategicamente, no horário de 15h00min, após o intervalo dos acadêmicos do curso de Medicina e de alguns funcionários do campus.

Utilizou-se para o desenvolvimento do estudo as cédulas de $R \$ 2,00 ; R \$ 5,00 ; R \$ 10,00 ; R \$ 20,00$ e $R \$ 50,00$ e um exemplar de todos os valores existentes em moedas $R \$ 0,05 ; R \$ 0,10 ; R \$ 0,25 ; R \$ 0,50$ e $R \$ 1,00$. Cada cédula e moeda foi acondicionada em um respectivo saco plástico virgem, de forma semelhante à utilizada por Neel (2012).

\subsection{Processamento das amostras (Contagem de Mesófilos)}

O material para a análise microbiológica foi coletado com o auxilio de um swab estéril umedecido em solução de cloreto de sódio ( $\mathrm{NaCl} \mathrm{0,9 \% ),} \mathrm{friccionando-o} \mathrm{com} \mathrm{movimentos} \mathrm{circulares} \mathrm{sobre} \mathrm{as} \mathrm{duas}$ superfícies das cédulas e moedas coletadas.

Em seguida, cada swab utilizado foi adicionado em um respectivo tubo de ensaio (10-1) (Presaí et al. 2008), contendo solução de cloreto de sódio ( $\mathrm{NaCl} 0,9 \%)$ e, posteriormente, esses tubos foram submetidos ao agitador vortex durante 30 segundos, para que ocorresse o desprendimento do material. 
A partir desses tubos $\left(10^{-1}\right)$, realizaram-se duas diluições decimais $\left(10^{-2}\right.$ e $\left.10^{-3}\right)$, que foram novamente submetidas ao agitador vortex, durante 30 segundos. Em seguida, $1 \mathrm{~mL}$ de cada diluição foi plaqueado pela técnica pour-plate sobre placas estéreis e, prontamente, após esse procedimento, foi adicionado sobre as placas o meio Agar Mueller-Hinton para crescimento dos mesófilos. Depois da solidificação do meio de cultura, as placas foram incubadas em estufa bacteriológica, com temperatura de $37^{\circ} \mathrm{C}$, pelo período de 24 horas. Após esse período, as placas foram retiradas da estufa e, depois, foi realizada a contagem das colônias e o valor foi expresso em UFC/cédula e UFC/moeda.

\section{RESULTADOS E DISCUSSÃO}

Não foi estabelecido um padrão de cédulas e notas a serem recolhidas e as mesmas foram trocadas aleatoriamente. No entanto, percebeu-se que, alguns exemplares, no decorrer das coletas, encontravam-se em perfeito estado de conservação e outros, em péssimo estado, semelhante à dinâmica de circulação que ocorre em outros locais que utilizam diretamente o dinheiro.

Do total de 15 moedas analisadas durante as três coletas, 13 (87\%) apresentaram-se contaminadas e 2 (13\%) não apresentaram contaminação.

Observou-se que todas as moedas apresentaram-se colonizadas, com exceção dos exemplares de $\mathrm{R} \$ 0,25$ e $\mathrm{R} \$ \mathbf{0 , 5 0}$ da $3^{\mathrm{a}}$ coleta, e, por conta disso, consequentemente, apresentaram as menores médias encontradas, sendo elas $10 \mathrm{UFC} /$ moeda e 6,6 UFC/moeda, respectivamente (Tabela 1).

No entanto, merece destaque a moeda de $\mathrm{R} \$ 1,00$, que apresentou $380 \mathrm{UFC} /$ moeda e média de 133,3 UFC/moeda; a moeda de R\$ 0,05, com 300 UFC/moeda e média de 116,6 UFC/moeda e, por último, o exemplar de R\$ 0,10 , com o quantitativo de $380 \mathrm{UFC/moeda} \mathrm{e} \mathrm{média} \mathrm{de} 50 \mathrm{UFC/moeda} \mathrm{(Tabela} \mathrm{1).}$

Tabela 1 - Quantificação das Unidades Formadoras de Colônias em moedas oriundas de uma cantina do UniFOA.

\begin{tabular}{|c|c|c|c|c|}
\hline moedas & $1^{\circ}$ Coleta & $2^{\circ}$ Coleta & $3^{\circ}$ Coleta & média de UFC/moedas \\
\hline 0,05 & 40 UFC/moeda & 10 UFC/moeda & 300 UFC/moeda & 116,6 UFC/moeda \\
\hline 0,10 & 30 UFC/moeda & 110 UFC/moeda & 10 UFC/moeda & 50 UFC/moeda \\
\hline 0,25 & 20 UFC/moeda & 10 UFC/moeda & *NHCB & 10 UFC/moeda \\
\hline 0,50 & 10 UFC/moeda & 10 UFC/moeda & *NHCB & 6,6 UFC/moeda \\
\hline 1,00 & 10 UFC/moeda & 10 UFC/moeda & 380 UFC/moeda & 133,3 UFC/moeda \\
\hline
\end{tabular}

Um fator a ser discutido e que, provavelmente, exerceu influência para o elevado número de colônias encontradas nos exemplares de $\mathrm{R} \$ 0,05$ e $\mathrm{R} \$ 1,00$ da $3^{\mathrm{a}}$ coleta, que apresentaram a quantidade de 300 UFC/moeda e 380 UFC/moeda, respectivamente, foi o tempo de circulação. Essas moedas tinham aparência de velhas, embora todas tivessem menos de 5 anos de uso. Segundo o Banco Central (2012), a vida útil das moedas é de, aproximadamente, 30 anos, sendo esse tempo ideal para que as moedas em circulação se desgastem e entrem em contato com diversos tipos de sujeira e outros elementos que favorecem para a formação de um substrato propício ao desenvolvimento bacteriano.

O baixo índice de desenvolvimento de UFC encontrados em todas as moedas da $1^{\text {a }}$ coleta; nos exemplares de $R \$ 0,05, R \$ 0,25, R \$ 0,50$ e $R \$ 1,00$ da $2^{a}$ coleta e nas moedas da $3^{a}$ coleta, nos 
exemplares de $R \$ 0,10, R \$ 0,25$ e $R \$ 0,50$ da, conforme expresso na (Tabela 1), pode ser pelo material que é utilizado para a confecção das mesmas, visto que possui potencial antimicrobiano. Segundo a instituição Banco Central (2013), órgão federal responsável pela emissão, distribuição e controle do meio circulante, as moedas em circulação ( $1^{\circ}$ e $2^{\circ}$ famílias) são cunhadas em material aço inoxidável; aço revestido de cobre e bronze; cupro-níquel; cupro-níquel (núcleo) e alpaca (anel); aço inoxidável (núcleo) e aço revestido de bronze (anel), sendo esses materiais conhecidos por sua resistência e por suas características antimicrobianas.

A relação entre quantidade de bactérias e o material com que as moedas são fabricadas também é ressaltado por Ukwuru; Gabriel (2012) e Espírito Santo et al. (2010), quando estes testaram o nível de resistência de bactérias a objetos de material metálico, isolando uma média de $6 \mathrm{UFC/moeda} \mathrm{de} 52$ moedas coletadas. Em concordância à Sudré et al. (2012), elementos metálicos, assim como os que compõem as nossas moedas, favorecem para a não adesão de bactérias à sua superfície, devido ao fato de ser mais difícil o desenvolvimento de ranhuras, porosidade e por não possuir característica absorvente.

Em referência às moedas de $\mathrm{R} \$ 0,25$ e $\mathrm{R} \$ 0,50$ da $3^{\mathrm{a}}$ coleta, que não apresentaram contaminação, é importante ressaltar que as mesmas encontravam-se em perfeito estado de conservação e sem a agregação de nenhum tipo de sujeira, indicando que, quanto mais novas e menos utilizadas, menores serão as quantidades de bactérias em sua superfície. Enemour et al. (2012), em sua pesquisa, afirmaram que o uso de amostras mais novas podem interferir diretamente nos resultados encontrados.

Comparando com outro estudo realizado por Presai et al. (2008), em Kathmandu, capital do Nepal, onde cédulas e moedas foram recolhidas de distintos locais, com elevada movimentação de pessoas, tais como mercearias, cantinas, hortifrúti, açougues, ônibus e peruas, foram analisadas e mostraram média de 507,3 UFC/moeda, sendo esse quantitativo muito superior ao encontrado neste estudo. Esse fato reforça que fatores como o material que compõe as cédulas e moedas, a localidade e, principalmente, as condições higiênico-sanitárias onde o dinheiro é circulado devem ser considerados, pois interferem intimamente sobre o quantitativo bacteriano encontrado.

Dessa forma, em plena concordância com Xu et al. (2005), que, ao analisarem culturas bacterianas extraídas de 17 moedas de diferentes países, identificando importantes patógenos de caráter oportunista como alguns representantes do gênero Bacillus spp. e algumas variedades do gênero Staphylococcus spp., concluíram, respaldados em seus resultados, que moedas podem hospedar diversos tipos de bactérias, geralmente em quantidades não significativas que, consequentemente, não oferecem riscos à saúde pública, no entanto, é importante que a população mantenha boas práticas de higiene, após manipulá-las.

Em se tratando das cédulas analisadas durante as três coletas realizadas, todas as 15 apresentaram-se contaminadas.

Os maiores quantitativos foram encontrados na cédula de $\mathrm{R} \$ 50,00$, que apresentou 13.800 UFC/ cédula e média de 4.873 UFC/cédula e na de $\mathrm{R} \$ 20,00$, que apresentou 380 UFC/cédula, com média de 213,3 UFC/cédula, ambas na $1^{\text {a }}$ coleta (Tabela 2).

$\mathrm{Na} 2^{\mathrm{a}}$ coleta, a nota de $\mathrm{R} \$ 10,00$ alcançou a quantidade de 1.000 UFC/cédula, obtendo a média de 426,6 UFC/cédula. No último dia, em relação aos dois anteriores, a evidência deve ser dada aos valores de $\mathrm{R} \$ 2,00$, com o quantitativo de 330 UFC/cédula e média de 146,6 UFC/cédula e nos de $\mathrm{R} \$ 5,00$, com 420 UFC/cédula, com média de 183,3 UFC/cédula (Tabela 2). 
Tabela 2 - Quantidade de colônias encontradas em cédulas.

\begin{tabular}{ccccc}
\hline cédulas & $\mathbf{1}^{\circ}$ Coleta & $2^{\circ}$ Coleta & $3^{\circ}$ Coleta & média de UFC/cédulas \\
\hline $\mathbf{2 , 0 0}$ & 40 UFC/cédula & 70 UFC/cédula & 330 UFC/cédula & 146,6 UFC/cédula \\
\hline $\mathbf{5 , 0 0}$ & 100 UFC/cédula & 30 UFC/cédula & 420 UFC/cédula & 183,3 UFC/cédula \\
\hline $\mathbf{1 0 , 0 0}$ & 200 UFC/cédula & 1000 UFC/cédula & 80 UFC/cédula & 426,6 UFC/cédula \\
\hline $\mathbf{2 0 , 0 0}$ & 380 UFC/cédula & 140 UFC/cédula & 120 UFC/cédula & 213,3 UFC/cédula \\
\hline $\mathbf{5 0 , 0 0}$ & 13.800 UFC/cédula & 460 UFC/cédula & 360 UFC/cédula & 4873 UFC/cédula \\
\hline \multicolumn{5}{c}{ Fonte: dos autores. }
\end{tabular}

Os fatores que colaboraram para a contaminação de todos os exemplares analisados, conforme mostrado na Tabela 2, são os mais diversos possíveis, sendo um deles a preferência da população ao uso de cédulas, fazendo com que elas sejam intensamente manipuladas, explicando o contingente bacteriano encontrado nesta pesquisa. Essa preferência ao uso de cédulas é confirmada também pelo órgão federal Banco Central (2007), que realizou pesquisa com 2.048 entrevistados das 26 capitais brasileiras, incluindo o Distrito Federal. A pesquisa revelou que a população brasileira prefere usar cédulas para pagamento de compras de baixo valor, em diversos tipos de estabelecimentos comerciais.

O Banco Central (2007) afırma que o tempo médio de circulação e durabilidade das cédulas é de 14 meses, porém, como não há como controlar a retirada e troca dessas cédulas em circulação, por conta do elevado número de exemplares disponibilizados, esse prazo acaba se excedendo até que as mesmas fiquem bem degradadas.

Barolia et al. (2011) e Ahmed et al. (2010), que encontraram em sua respectivas pesquisas, a presença de colônias de importantes patógenos como Staphylococcus aureus; Shigella dysenteriae; Escherichia coli e Enterobacter aerogenes, ressaltam que é importante se atentar para o uso de cédulas velhas, remendadas e sujas, pois estas são as mais favoráveis ao desenvolvimento de diversos tipos de bactérias e podem ser consideradas potencialmente perigosas, sendo essa a razão para o elevado número de bactérias encontradas nas cédulas de $R \$ 5,00, R \$ 10,00$ e $R \$ 20,00$ e $R \$ 50,00$ da $1^{\text {a }}$ coleta; $R \$ 10,00, R \$ 50,00$ e 20,00 da $2^{a}$ coleta e nas cédulas da $3^{a}$ coleta, sendo elas $R \$ 5,00, R \$ 50,00, R \$$ 2,00 e $R \$ 20,00$, conforme expresso na Tabela 2 .

Outro elemento a ser questionado e que exerce influência no desenvolvimento de agentes patogênicos e no resultado encontrado é o tipo de material que é utilizado na confecção das cédulas, pois segundo Vriesekoop et al. (2010) e Sudré et. al. (2012), materiais com características mais porosas e até mesmo absorventes, assim como os da cédulas em circulação, facilitam de forma significativa o crescimento de agentes e, consequentemente, a transmissão de diversos tipos de bactérias.

Enfım, é relevante salientar que o local em que as cédulas são recolhidas podem interferir no quantitativo bacteriano, como pode ser confirmado por Kawo et al. (2009) que recolheram, aleatoriamente, um total de 140 Nairas, moeda oficial e circulante na cidade de Kano, na Nigéria, oriundas de diferentes localidades tais como ônibus; taxis; comércios; empresas; vendas ambulantes e em um mercado local, encontrando uma média de $3,59 \times 10^{2} \mathrm{UFC} / \mathrm{ml}$ a $1,29 \times 10^{9} \mathrm{UFC} / \mathrm{ml}$, sendo esse resultado semelhante ao de Feglo e Nkansah (2010), que isolaram uma média de 4,0 $\times 10^{4}$ nas cédulas de GHç1; 1,8 $\times 10^{4}$, nas

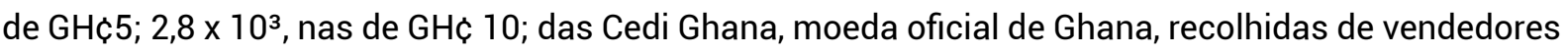
ambulantes, que manipulavam os alimentos que comercializavam juntamente com as cédulas. 


\section{CONCLUSÃO}

A partir dos resultados apresentados, podemos concluir que as cédulas e moedas usadas neste estudo apresentaram-se contaminadas, podendo assim ser consideradas importantes agentes transmissores de diversos tipos de bactérias, sendo que as cédulas, em relação às moedas, podem ser consideradas mais eficientes em tal ação. Essa condição encontrada permite-nos dizer que a contaminação é um risco à saúde pública

\section{REFERÊNCIAS}

AHMED, S. U. et al. Evaluation of the Microbial Contamination of Bangladesh Paper Currency Notes (Taka) in Circulation. Advances in Biological Research, v. 4, n. 5, p. 266-271, 2010.

AWE, S. et al. Bacteriological quality of some Nigerian currencies in circulation. African Journal of Microbiology Research, v. 4, n. 21, p. 2231-2234, 2010.

BANCO CENTRAL DO BRASIL. Moedas do Real (Segunda e Primeira família), 2013. Disponível em:<http:// www.bcb.gov.br/?MOEDAREAL> Acesso em: 3 Out. 2013.

BANCO CENTRAL DO BRASIL. Pesquisa de qualidade de cédulas e estouramento de moedas metálicas, 05 de Dezembro 2011 e 12 de Janeiro de 2012. Disponível em: < http://www.bcb.gov.br/htms/mecir/ Pesquisa_Qualidade_das_Cedulas_e_Entesouramento_de_Moedas_2012.pdf>Acesso em: 4 Out. 2013.

BANCO CENTRAL DO BRASIL. 0 brasileiro e sua relação com o dinheiro II, 2007. Disponível em:<http:// www.abbc.org.br/arquivos/apresentacao_bacen_datafolha_resumo2007.pdf> Acesso em: 4 Out. 2013.

BAROLIA, S. K. et al. Coliform Contamination on different Paper Currency in Ajmer, Rajasthan, India. Universal Journal of Environmental Research and Technology, v. 1, p. 552-556, 2011.

ENEMOUR, S. C. et al. Microbial contamination of currency counting machines and counting room environment in selected commercial banks. Scientific Research and Essays, v. 7, n. 14, p. 1508-1511, 2012.

ESPÍRITO SANTO, C. et al. Isolation and Characterization of Bacteria Resistant to Metallic Copper Surfaces. Applied and environmental microbiology, v. 76, p. 1341-1348, 2010.

FERREIRA, D. M. et. al. Análise Microbiológica de cédulas circulantes em Feira Livre do Município de Belford Roxo-RJ. Revista Saúde Física \& Mental-UMIABEU, v. 1, n. 1, p. 11-14, 2012.

KAWO, A. H. et al. Prevalence and public health implications of the microbial load of abused naira notes. Bayero Journal of Pure and Applied Sciences, v. 2, n. 1, p. 52 - 57, 2009.

NEEL, R. Bacteriological Examination of Paper Currency Notes in Tanga in Tanzania. Internacional Journal of Pharmaceutical Sciences Review and Research, v. 16, n. 2, p. 9-12, 2012.

PRESAI, T. et al. Microbial Load on Paper/Polymer Currency and Coins. Nepal Journal of Science and Technology, n. 9, p. 105-109, 2008. 
REIS, G. M. et al. Contaminação Microbiana de Telefones Celulares de Acadêmicos de uma Universidade do Sul do Brasil. XIII Mostra de iniciação Científica- XVIII Seminário Interinstitucional de Ensino, Pesquisa e Extensão Unicruz - Cruz Alta - RS, 2010.

SOUZA, A. C. et al. Microorganismos Encontrados em Dinheiro Brasileiro Coletado em Feira Livre. Revista NewsLab, v. 77, p. 178-186, 2006.

SUDRÉ, A. P. et al. Estudo da contaminação de moedas e cédulas de dinheiro circulantes na cidade de Niterói- RJ. Revista de patologia tropical, v. 41, n. 4, p. 465-470, 2012.

UKWURU, M.; GABRIEL, A. Cross contamination between food and money due to simultaneous handling. Journal of Applied Science and the Environment, v. 3, p. 42-48, 2012.

VRIESEKOOP, F. et al. Dirty Money: An investigation into the hygiene status of some of the world's currencies as obtained from food outlets. Foodborne Pathogens and Disease, v. 7, n. 12, p. 1497- 1502, 2010.

$\mathrm{XU}$, J. et al. Ribosomal DNA (rDNA) identification of the culturable bacterial flora on monetary coinage from 17th currencies. Journal of Environmental Health, v. 67, n. 7, p. 51-55, 2005. 